\title{
Original syu \\ Horizontal transmission of hepatitis B virus among adults in a rural village in Kollam district, southern India
}

\author{
Rakesh PS, Sherin Daniel, Hari Sankar, Subhagan S, Shaji M, \\ Salila K
}

District Medical Office, Kollam,

Kerala, India

\begin{abstract}
Background and aim: Hepatitis B virus (HBV) infections have been consistently reported over the last few years from the two wards of Thrikkaruva, Kollam district, Kerala, southern India. This study was conducted to determine the risk factors associated with HBV transmission in Thrikkaruva.

Methods: This was a community based, case-control study, enrolling HBsAg positive cases diagnosed since January 2010. Controls were age (+5years) and sex matched neighbourhood individuals. Data was collected using a questionnaire and all subjects were investigated for $\mathrm{HBsAg}$, anti-HBs and anti-HBc. Local healthcare institutions serving the community were surveyed for infection control practices. Statistical analysis for HBV associated factors was carried out.

Results: A total of 49 cases and 49 controls were included in the final analysis. Logistic regression revealed close personal contact with of a case of hepatitis B (adjusted OR: 3.09, 95\% CI: 1.13-9.40) as a significant risk factor in the community. Qualitative examination of infection control practices at private clinics, barber shops and dental clinics revealed conditions conducive for HBV transmission in the community.

Conclusions: Our study reveals active horizontal person-to-person HBV transmission in the village. Comprehensive action including vaccination of all susceptible contacts, promotion of infection control at health care institutions, and raising public awareness are recommended in this region.
\end{abstract}

Correspondence:

Dr Rakesh PS

Email: rakeshrenjini@gmail.com

KEYWORDS: Hepatitis B, horizontal transmission, injection safety, iatrogenic infections

\section{Introduction}

Over two billion people across the world are infected with hepatitis B (HBV) and about 240 million suffer from chronic liver infections. Acute and chronic complications of hepatitis B causes nearly six hundred thousand deaths a year. ${ }^{1-3} 15-25 \%$ patients with chronic hepatitis B develop serious hepatic complications including liver cirrhosis, hepatic failure and liver cancer. ${ }^{4}$ The World Health Organization estimates 2-5\% of the general population in the Indian subcontinent to be chronically 
infected with hepatitis B. ${ }^{1}$ The findings from a meta-analysis indicate an $\mathrm{HBV}$ point prevalence of $2.4 \%$ (95\% CI: 2.2-2.7\%) in India. ${ }^{5}$

The Integrated Disease Surveillance Project (IDSP) was initiated by the Government of India in 2004. ${ }^{6}$ It includes field, hospital and laboratory based disease surveillance for priority diseases identified by the project. Hepatitis B cases have been consistently reported over the last few years from two wards of Thrikkaruva Panchayat, Kollam district, Kerala in southern India. A primary health care team conducted preliminary investigations including active search for symptomatic old and new cases in the community and organized two free hepatitis B detection camps. The community and the local government have been motivated to contain the transmission of this disease in the region.

This study was conducted to determine the risk factors associated with HBV transmission in the Thrikkaruva Panchayat. Identification of the risk factors can help to develop a comprehensive strategy to prevent blood borne pathogen transmission in the area.

\section{Methods}

The Thrikkaruva Panchayat is situated in Chittumala block, Kollam Taluk in Kollam district with a population of 23,122. The literacy rate of the region is $89.95 \%$. It has 16 wards. Healthcare is provided by a primary health centre, a private hospital and a few private clinics. Our study was a community based case-control study. Cases were defined as HBsAg positive permanent residents of the region, diagnosed since January 2010. These cases were picked up by the routine surveillance system. A line list of cases was prepared after active door to door search for symptomatic old and new cases. Pregnant women and individuals with chronic illness were excluded. Controls included age (+/-5years) and sex matched neighbours from the same community. Any control found HBV infected on blood investigation was excluded from the study. Given that an approximate $10 \%$ of controls were exposed to intravenous injections over the last six months and a $40 \%$ proportion of cases, the study sample size for an $80 \%$ power was calculated to be 42 subjects in each arm.

Data was collected by interviewing cases and controls at their home using a structured questionnaire. The questionnaire was designed based on literature review, expert opinion and frequent discussions with the health workers of the area. The questionnaire included basic demography, details of injections, blood investigations, blood donations, intravenous drug use, surgeries, skin piercing, details of visit to hospitals, dental clinics and barber shops and family history of hepatitis. Close personal contact was defined as contact with tears, saliva, blood, open wounds, mucous membrane or skin of a hepatitis $\mathrm{B}$ case. The socioeconomic status was assessed based on type of ration cards issued by the government. The questionnaire was pilot tested before use. Two males and two females with Bachelors in Social Work were given two-day training in data collection. Female social workers interviewed female subjects and vice versa. Establishing a good rapport was crucial before commencing an interview. Care was taken to provide utmost privacy during the interview. The risk factors were assessed within a time frame of six months before the diagnosis of the disease. Written informed consent was obtained from all subjects. Cases and control were invited for blood investigations for $\mathrm{HBsAg}$, anti-HBs and anti-HBc arranged on two fixed days at a local venue. Pre-test counselling was provided before collecting blood samples. Local institutions providing healthcare to the community were mapped with the help of health workers and study subjects. Visits were made to two private laboratories, three private hospitals, three dental clinics, one barber shop, one beauty salon and two private clinics. Findings were recorded using a previously prepared check list to assess infection control practices. The data was entered into the Epi Info software and analyzed using SPSS v12. Univariate analyses for HBV risk factors were reported as odds ratio and $95 \%$ confidence intervals. Variables with $\mathrm{p}<0.2$ were used to compute a backward conditional logistic regression model.

\section{Results}

There were 54 cases on the line list. Fifty-one were interviewed, two being unavailable and one having relocated out of the village. Two cases did not show any evidence of HBV and were excluded from further analysis. The mean age of cases was 47.2 years (SD: 13.69 ; range: $20-74$ ). The socio-demographic characteristics of the study population are summarised in Table 1. Majority of the HBV cases were from ward XII. Ward X and XIII, which were located near to XII also reported cases. The date of diagnosis was collected and a time distribution was drawn with quarterly intervals (Figure 1). Infections peaked during 2011 in quarters 2 to 4 , and then tapered to 2-3 cases in every subsequent quarter.

Blood sample were tested for 41 cases and 32 controls. 
Table 1: Socio-demographic characteristics of cases and controls

\begin{tabular}{|c|c|c|}
\hline Characteristics & $\begin{array}{l}\text { Cases } \\
(\mathrm{N}=49)\end{array}$ & $\begin{array}{l}\text { Controls } \\
(\mathrm{N}=49)\end{array}$ \\
\hline \multicolumn{3}{|l|}{ Age } \\
\hline - 20-29 years & $6(12.2 \%)$ & $7(14.3 \%)$ \\
\hline - 30-39 years & $9(18.4 \%)$ & $9(18.4 \%)$ \\
\hline - 40-49 years & $12(24.5 \%)$ & $11(22.4 \%)$ \\
\hline - 50-59 years & $12(24.5 \%)$ & $12(24.5 \%)$ \\
\hline - $60-69$ years & $7(14.3 \%)$ & $9(18.3 \%)$ \\
\hline - 70-79 years & $3(6.1 \%)$ & $1(2.0 \%)$ \\
\hline \multicolumn{3}{|l|}{ Gender } \\
\hline - Male $33(67.4 \%)$ & $33(67.4 \%)$ & \\
\hline - Female $16(32.7 \%)$ & $16(32.7 \%)$ & \\
\hline \multicolumn{3}{|l|}{ Marital Status } \\
\hline - Living with spouse & $41(83.7 \%)$ & $36(73.5 \%)$ \\
\hline • Unmarried & $7(14.3 \%)$ & $7(14.3 \%)$ \\
\hline • Living abroad & - & $1(2.0 \%)$ \\
\hline - Widowed/separated & $1(2.0 \%)$ & $5(10.2 \%)$ \\
\hline \multicolumn{3}{|l|}{ Educational status } \\
\hline - $<8^{\text {th }}$ standard & $3(6.1 \%)$ & $5(10.2 \%)$ \\
\hline - $8-10^{\text {th }}$ standard & $33(67.3 \%)$ & $28(57.1 \%)$ \\
\hline - $>10^{\text {th }}$ standard & $13(26.5 \%)$ & $14(28.6 \%)$ \\
\hline \multicolumn{3}{|l|}{$\underline{\text { Socioeconomic Status }}$} \\
\hline - Below poverty line & $11(22.4 \%)$ & $12(24.5 \%)$ \\
\hline - Above poverty line & $38(77.6 \%)$ & $37(75.5 \%)$ \\
\hline
\end{tabular}

None of the controls showed evidence of hepatitis B infection. Based on the blood investigation results a diagnosis of early acute HBV infection was made in 2/41, acute or chronic HBV infection with virus not cleared in $6 / 41$ and previous HBV infection with virus cleared and immunity in 31/41 cases. Nine houses had more than one hepatitis B case. The relationship was not spousal in eight of these households. These cases

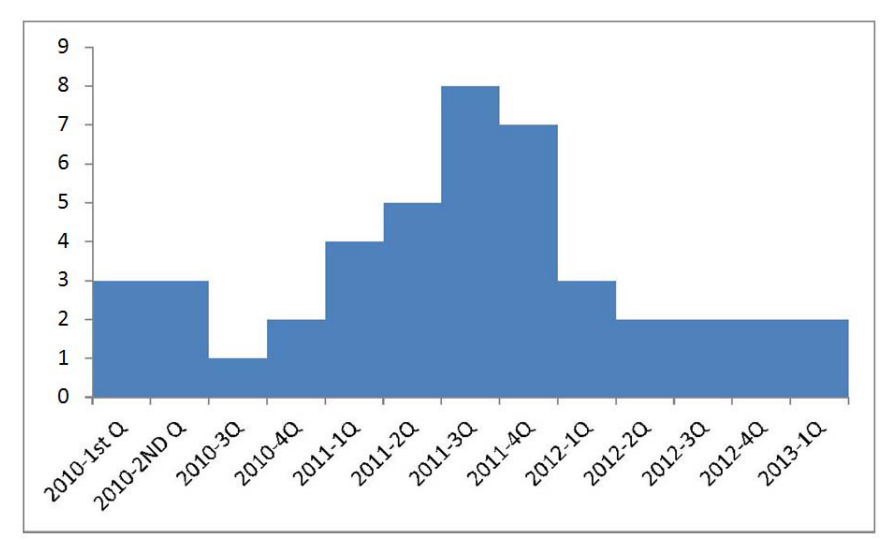

Figure 1: Time distribution of hepatitis B cases (date of diagnosis) at Thrikkaruva

were first degree relatives (mother-child 2/9, father-child 4/9, siblings 2/9). The difference in date of onset of the disease among family members was more than six months apart in eight of these households.

$40.8 \%$ cases and $22.4 \%$ controls had a hepatitis B patient residing with them $(\mathrm{p}=0.041)$. Among cases, $37.4 \%$ reported close personal contact (via tears, saliva, sweat, blood, and/or open wounds) with a known hepatitis B case, while $14.3 \%$ controls ( $\mathrm{p}=0.017$ ) gave such history. $71.4 \%$ cases and $59.2 \%$ controls received injections $(\mathrm{p}=0.144)$. Univariate factors associated with hepatitis B status are shown in Table 2. Close personal contact with a case of hepatitis B (adjusted OR: 3.09, 95\% CI: 1.13-9.40) was identified as a significant risk factor associated with HBV infection (Table 3).

In subgroup analysis, $84.2 \%$ of the cases occurred before $1^{\text {st }}$ January 2012, and reported having received an injection within six months prior to onset of symptoms, while only $27.3 \%$

Table 2: Univariate analysis of risk factors for hepatitis B at Thrikkaruva

\begin{tabular}{lllll}
\hline Characteristics & $\begin{array}{l}\text { Cases } \\
(\mathbf{N}=\mathbf{4 9})\end{array}$ & $\begin{array}{l}\text { Controls } \\
(\mathbf{N}=\mathbf{4 9})\end{array}$ & $\begin{array}{l}\text { P value } \\
\text { Odds ratio } \\
(\mathbf{9 5 \%} \mathbf{C I})\end{array}$ \\
\hline Hepatitis B cases in the family & $20(40.8 \%)$ & $11(22.4 \%)$ & 0.041 & $2.38(1.02-5.74)^{*}$ \\
Close contact with a case of hepatitis B & $17(34.7 \%)$ & $7(14.3 \%)$ & 0.017 & $3.18(1.18-8.60)^{*}$ \\
Injection & $35(71.4 \%)$ & $29(59.2 \%)$ & 0.144 & $1.72(0.74-4.00)$ \\
Dentist & $6(12.2 \%)$ & $4(8.1 \%)$ & 0.370 & $1.57(0.41-5.95)$ \\
Sharing toothbrush & $3(6.1 \%)$ & $1(2 \%)$ & 0.309 & $3.13(0.31-31.19)$ \\
Surgery & $9(18.4 \%)$ & $4(8.2 \%)$ & 0.116 & $2.53(0.72-8.85)$ \\
Blood transfusion & $7(14.3 \%)$ & $2(4.1 \%)$ & 0.081 & $3.91(0.77-19.90)$ \\
Skin piercing procedure & $7(14.3 \%)$ & $3(6.1 \%)$ & 0.159 & $2.55(0.62-10.52)$ \\
Blood investigation from a laboratory & $26(53.1 \%)$ & $23(46.9 \%)$ & 0.341 & $1.278(0.57-2.82)$ \\
Visit to barber shop & $29(59.2 \%)$ & $27(55.1 \%)$ & 0.419 & $1.18(0.53-2.63)$ \\
Hospitalisation for at least 4 hrs & $15(30.6 \%)$ & $10(20.4 \%)$ & 0.177 & $1.72(0.68-4.33)$ \\
Bite by deer fly & $26(53.1 \%)$ & $25(51 \%)$ & 0.500 & $1.08(0.49-2.39)$ \\
Extra/pre-marital sex & $3(6.1 \%)$ & $4(8.2 \%)$ & 0.500 & $0.73(0.15-3.46)$ \\
\hline
\end{tabular}

$* \mathrm{p}<0.05$ 
Table 3: Logistic regression model for risk factors of hepatitis B at Thrikkaruva

\begin{tabular}{lcl}
\hline Characteristics & Adjusted odds ratio & 95\% CI \\
\hline $\begin{array}{l}\text { Close contact with of a } \\
\text { case of hepatitis B }\end{array}$ & 3.09 & $1.13-9.40^{*}$ \\
Blood transfusion & & \\
Skin piercing procedure & 4.61 & $0.89-25.01$ \\
Hepatitis B cases in the family & 1.52 & $0.29-7.85$ \\
Surgery & 1.78 & $0.61-4.80$ \\
\hline
\end{tabular}

*p $<0.05$

of recently diagnosed cases had the history of injections ( $p$ $<0.01)$. The prevalence of risk factors in both groups is shown in (Table 4). Among the controls, 16.3\% (8/49) had received hepatitis $B$ vaccine. Of these seven were tested and five were found positive for anti-HBsAg.

Institutional surveys revealed lack of a qualified technician in one of the laboratories. The available 'technicians' were not vaccinated against hepatitis B and did not use gloves while working in the lab. Disposal of sharps were unsatisfactory in one of the laboratories. Four needles were found in the boiler in a hospital giving the impression that needles were being reused. All institutions had poor remedial action for managing blood spills. Sterilizer/autoclave was not available in 1/3 dental clinics. The sterilization of instruments was unsatisfactory in 2/3 dental clinics. Needles were being reused for giving local anesthesia in 1/3 dental clinics. An unqualified practitioner was prescribing and unqualified staff was administering injections in one of the busiest private clinics. At the barber shop, although the razor blades were being changed, the blade holder was not washed in between procedures.

\section{Discussion}

The most significant risk factor for hepatitis B transmission in our case-control study was close personal contact with body fluids (tears, saliva, sweat, blood, open wounds) of a HBV infected individual, suggesting active horizontal person-toperson HBV transmission in the community. Injections, surgery, blood transfusions, skin piercings were higher among cases as compared to controls, though not statistically significant. There might have been associations between these risk factors and HBV status that we were unable to detect due to small sample size. Also, overmatching could have introduced bias for visits to the barber shop, as there were only a very few of those institutions to which people in the community approached. The qualitative study on infection control practices at private clinics, barber shops and dental clinics confirmed conducive circumstances for HBV transmission in the community.

Subgroup analysis showed high exposure to injections among HBV infected especially before 2012 (84\%) as compared to those with disease onset after January 2012 (27\%) and as compared to controls (59\%). Given the pattern of epidemic curve it is tempting to postulate the presence of a common source during late 2010 to early 2011. This could be unsafe injections practiced in the village. The peak could also be due to improved surveillance or awareness among the community. However, currently the horizontal transmission seems to be the major source of infection among family members, friends and neighbours. HBV may spread through contact with body fluids. Indirect contact with blood-contaminated surfaces can also transmit HBV. ${ }^{12-14} \mathrm{HBV}$ can survive and remain infectious in dried blood on inanimate surfaces at room temperature for at least 1 week and probably longer. ${ }^{15}$ Intra-familial transmission of hepatitis B has been documented in previous studies. ${ }^{16-18} \mathrm{~A}$ study from north India identified predominant horizontal HBV transmission.. ${ }^{19}$ The specific modality of horizontal transmission

Table 4: Prevalence of risk factors by year of onset of hepatitis B cases

\begin{tabular}{|c|c|c|c|}
\hline$\overline{\text { Risk factor }}$ & $\begin{array}{c}\text { Disease onset before Jan } 1^{\text {st }} 2012 \\
(n=38)\end{array}$ & $\begin{array}{c}\begin{array}{c}\text { Disease onset after Jan } 1^{\text {st }} 2012 \\
(n=11)\end{array}\end{array}$ & P value \\
\hline Hepatitis B cases in the family & $18(47.4 \%)$ & $2(18.2 \%)$ & 0.080 \\
\hline Close contact with a case of hepatitis B & $13(34.2 \%)$ & $4(36.4 \%)$ & 0.582 \\
\hline Injection & $32(84.2 \%)$ & $3(27.3 \%)$ & 0.001 \\
\hline Dentist & $4(10.5 \%)$ & $2(18.2 \%)$ & 0.112 \\
\hline Surgery & $8(21.1 \%)$ & $1(9.1 \%)$ & 0.341 \\
\hline Blood transfusion & $5(13.2 \%)$ & $2(18.2 \%)$ & 0.500 \\
\hline Skin piercing procedure & $7(18.4 \%)$ & - & \\
\hline Blood investigation from a laboratory & $20(52.6 \%)$ & $06(54.5 \%)$ & 0.592 \\
\hline Visit to barber shop & $25(65.8 \%)$ & $4(36.4 \%)$ & 0.082 \\
\hline Hospitalisation for at least 4 hours & $14(36.8 \%)$ & $01(9.1 \%)$ & 0.077 \\
\hline Bite by deer fly & $19(59.4 \%)$ & $7(49.2 \%)$ & 0.408 \\
\hline
\end{tabular}


is unknown but it may be due to contact of non-intact skin or mucous membranes with tears, saliva or blood containing secretions. Importance of hand washing cannot be overemphasized for hepatitis B prevention.

It is estimated that unsafe injections may cause 8-16 million HBV infections each year worldwide, most of which occur in developing countries. ${ }^{20}$ Unsafe injections have been identified as a cause for many HBV outbreaks in India. ${ }^{21,22} \mathrm{~A}$ similar proportion of controls and cases received injections in our study and might be the reason for a lack of association with HBV. $59 \%$ of the controls had received an injection over the last six months. This is very high, especially in a setting where there are evident deficiencies in the standards of infection control practices. Ongoing campaigns for reducing unnecessary use of injections and increasing public awareness for healthcare safety are imperative for this region.

Hepatitis B vaccination is the most effective means of preventing infection. Integration of the vaccine into the childhood vaccination schedule has been shown to interrupt transmission..$^{23,24}$ There are no cases reported among children in this area. The hepatitis B vaccine has been part of the UIP since 2004 in this village. The protection provided by the vaccine could be one reason for low incidence among children. It could also be due to the asymptomatic or subclinical disease. Hepatitis B vaccination has to be given to all household contacts of a hepatitis B patient in this region.

The State lacks a policy for regulating private clinical laboratories, dental clinics and hospitals. Blood investigations carried out over last six months was identified as a risk factor for acquiring hepatitis B in a previous study from Kollam district. ${ }^{25}$ Very few clinical laboratories in India have been found to participate in external quality assurance programs. ${ }^{26}$ It is high time for a state health policy for regulating private institutions; emphasizing quality assurance and such a policy should be backed by legislation.

The strengths of our study include its community setting, standardized procedures and appropriate design. However the study has several limitations. Recall bias and interviewer bias would have affected the results. Risk factors were assessed with a time frame related to the date of diagnosis of the HBV infection and the exact time of disease onset may not be the same. The standardization procedure and the structured questionnaire would have helped to reduce the bias to some extent. Many asymptomatic cases would not have been picked up by the surveillance system. Screening camps have been conducted two times in the village previously, but no new cases were detected. Also none of the controls proved to be infected on blood investigations.

To summarize, the most significant risk factor for hepatitis B transmission in the study was contact with body fluids of an HBV case suggesting active horizontal person-to-person HBV transmission in the community. Horizontal transmission plays an important role in contributing to the high prevalence of $\mathrm{HBV}$, especially in endemic pockets. A comprehensive program including vaccination for all susceptible contacts, promotion of infection control at health care institutions, and raising public awareness is needed for this region.

\section{Acknowledgements}

Dr Abhiraj, Mr Bijuben, Mr Abhilash, Mr Vijeesh and leaders of Thrikkaruva Grama Panchayat. The study was conducted with the financial assistance of State Health System Resource Center, Kerala.

\section{References}

1. World Health Organization. Hepatitis B. Fact Sheet 204. [Internet] Geneva: World Health Organization; 2012 [cited 2013 October 30]. Available from: http://www.who.int/mediacentre/factsheets/ fs $204 / \mathrm{en} /$

2. Goldstein ST, Zhou F, Hadler SC, Bell BP, Mast EE, Margolis HS. A mathematical model to estimate global hepatitis B disease burden and vaccination impact. Int $J$ Epidemiol. 2005;34:1329-39.

3. Ganem D, Prince AM. Hepatitis B virus infection-natural history and clinical consequences. $N$ Engl J Med. 2004;350:1118-29.

4. Centers for Disease Control. Hepatitis B- general information [Internet] Atlanta: Department of Health \& Human Services. Centers for Disease Control and Prevention; 2010 [cited 2013 October 30]. Available from: http://www.cdc.gov/hepatitis/hbv/ pdfs/hepbgeneralfactsheet.pdf

5. Batham A, Narula D, Toteja T, Sreenivas V, Puliyel JM. Sytematic review and meta-analysis of prevalence of hepatitis B in India. Indian Pediatr. 2007;44:663-74.

6. Government of India. Integrated Disease Surveillance Project. [Internet] New Delhi: Ministry of Health and Family welfare [cited 2013 October 30]. Available from: http://www.idsp.nic.in/

7. Lok AS, McMahon BJ. Chronic hepatitis B: update 2009. Hepatology. 2009;50:661-2.

8. Sorrell MF, Belongia EA, Costa J, Gareen IF, Grem JL, Inadomi $\mathrm{JM}$, et al. National Institutes of Health consensus development conference statement: management of hepatitis B. Hepatology. 2009;49:S4-S12.

9. Hollinger FB, Liang TJ. Hepatitis B virus. In: Knipe DM, Howley PM, Griffin DE, Lamb RA, Martin MA, Roizman B, editors. Fields Virology, 4th ed. Philadelphia: Lippincott 
Williams \& Wilkins; 2001.p.2971-3036.

10. Robinson WS. Hepatitis B virus and hepatitis D virus. In: Mandell GL, Bennett JE, Dolin R, editors. Principles and practice of infectious diseases, 4th ed. New York: Churchill Livingstone; 1995.p.1406-39.

11. Tran TT, Martin P. Hepatitis B: epidemiology and natural history. Clin Liver Dis. 2004;8:255-66.

12. Thompson ND, Perz JF. Eliminating the blood: ongoing outbreaks of hepatitis B virus infection and the need for innovative glucose monitoring technologies. J Diabetes Sci Technol. 2009;3:283-8.

13. Centers for Disease Control and Prevention (CDC). Guideline for isolation precautions: preventing transmission of infectious agents in healthcare settings 2007. Atlanta (GA): US Department of Health and Human Services. CDC; 2007.

14. Centers for Disease C, Prevention. Transmission of hepatitis B virus among persons undergoing blood glucose monitoring in longterm-care facilities-Mississippi, North Carolina, and Los Angeles County, California, 2003-2004. MMWR Morb Mortal Wkly Rep. 2005;54:220-3.

15. Bond WW, Favero MS, Petersen NJ, Gravelle CR, Ebert JW, Maynard JE. Survival of hepatitis B virus after drying and storage for one week. Lancet. 1981;1:550-1.

16. Salkic NN, Zildzic M, Muminhodzic K, Pavlovic-Calic N, Zerem E, Ahmetagic S, et al. Intrafamilial transmission of hepatitis B in Tuzla region of Bosnia and Herzegovina. Eur J Gastroenterol Hepatol. 2007;19:113-8.

17. Erol S, Ozkurt Z, Ertek M, Tasyaran MA. Intrafamilial transmission of hepatitis B virus in the eastern Anatolian region of Turkey. Eur J Gastroenterol Hepatol. 2003;15:345-9.

18. Mohammad Alizadeh AH, Ranjbar M, Ansari S, Alavian SM, Shalmani HM, Hekmat L, et al. Intra-familial prevalence of hepatitis B virologic markers in $\mathrm{HBsAg}$ positive family members in Nahavand, Iran. World J Gastroenterol. 2005;11:4857-60.

19. Gupta S, Gupta R, Joshi YK, Singh S. Role of horizontal transmission in hepatitis B virus spread among household contacts in north India. Intervirology. 2008;51:7-13.

20. Kane A, Lloyd J, Zaffran M, Simonsen L, Kane M. Transmission of hepatitis $\mathrm{B}$, hepatitis $\mathrm{C}$ and human immunodeficiency viruses through unsafe injections in the developing world: model-based regional estimates. Bull World Health Organ. 1999;77:801-7.

21. Singh J, Gupta S, Khare S, Bhatia R, Jain DC, Sokhey J. A severe and explosive outbreak of hepatitis B in a rural population in Sirsa district, Haryana, India: unnecessary therapeutic injections were a major risk factor. Epidemiol Infect. 2000;125:693-9.

22. Singh J, Bhatia R, Patnaik SK, Khare S, Bora D, Jain DC, et al. Community studies on hepatitis B in Rajahmundry town of Andhra Pradesh, India, 1997-8: unnecessary therapeutic injections are a major risk factor. Epidemiol Infect. 2000;125:367-75.

23. Centers for Disease Control and Prevention. Hepatitis B virus: A comprehensive strategy for eliminating transmission in the United States through universal childhood vaccination: recommendations of the immunization practices advisory committee (ACIP). MMWR Morb Mortal Wkly Rep.1991;40:1-19.

24. Van Damme P, Kane M, Meheus A. Integration of hepatitis B vaccination into national immunisation programmes. Viral Hepatitis Prevention Board. BMJ. 1997;314:1033-6.

25. Rakesh PS, Usha S, Renjini BA, Subhagan S, Shaji M. Risk factors of hepatitis B infection: a community based case control study from southern India. Ind J Basic App Med Res. 2013;3:172-80.

26. Thakur VS. Total Quality Management, Laboratory Accreditation and External Quality Assessment Schemes. Jugoslov Med Biohem. 2004;23:311-5. 